\title{
Communication and interactions in cloud platform subtitling
}

\author{
Irene Artegiani
}

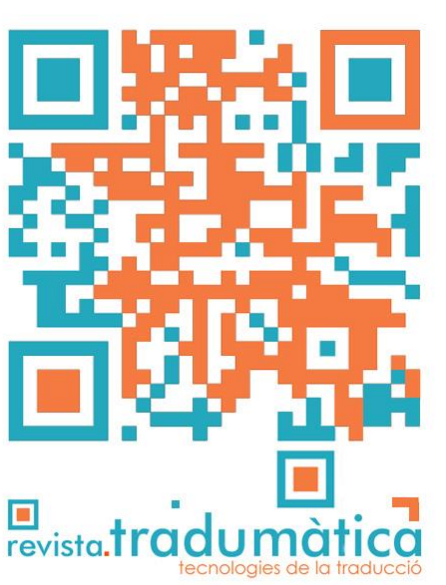

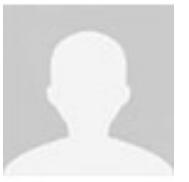

Irene Artegiani

University of Roehampton artegiai@roehampton.ac.uk; ORCID:

0000-0000-0000-0000

\section{Abstract}

This article explores recent developments in freelance subtitling work within the audio-visual translation (AVT) industry. During the 2010s, many LSPs operating globally moved their provision of paid, professional subtitling services to cloud platforms, and I argue that such platforms, while capable of generating collaborative environments, enact information patterns which weaken the communicative and collaborative aspects of production processes, while running the risk of compromising the quality of the subtitlers' position.

Keywords: subtitling, cloud platform, communication, trust, industry, information asymmetry

\section{Resumen}

Este artículo explora los cambios recientes que ha experimentado el trabajo de los subtituladores autónomos dentro de la industria de la traducción audiovisual. Durante la década de 2010, muchos proveedores de servicios lingüísticos que operan a nivel internacional han trasladado sus servicios de subtitulación profesional remunerada a plataformas en la nube (Sakamoto, 2018). Me propongo argumentar que estas plataformas, si bien generan entornos de colaboración, adoptan pautas de comunicación e información que menoscaban los aspectos colaborativos de los procesos de producción, lo cual puede comprometer el papel de los subtituladores en términos cualitativos.

Palabras clave: subtitulación; plataforma en la nube, industria; comunicación: colaboración; prácticas

\section{Resum}

Aquest article explora l'actual desenvolupament del treball autònom de subtitulació dins la indústria de la traducció audiovisual (TAV). Durant la dècada de 2010, molts proveïdors de serveis lingüístics (PSL) que operen a nivell internacional han traslladat la seva prestació de serveis de subtitulació professionals de pagament a plataformes al núvol (Sakamoto, 2018). El nostre objectiu és argumentar que aquestes plataformes, tot i que són capaces de generar entorns collaboratius, adopten patrons de comunicació i informació que debiliten els aspectes collaboratius dels 
processos de producció, amb el risc de comprometre la qualitat del càrrec dels subtituladors.

Paraules clau: subtitulació; plataforma al núvol, indústria; comunicació: colllaboració; pràctiques

\section{Introduction}

In recent decades, creative jobs like translation and audio-visual translation (AVT) have undergone processes of massification and commoditisation, not so different from those which characterised factory productions a century ago. Such processes are aimed at identifying and maintaining both productivity and quality levels across mass productions, and in order to do this, jobs have to be broken down and redefined into smaller, standardised units. By doing so, tasks can be reconfigured as companies deem appropriate, and performance indicators can be applied to each unit of work, facilitating the introduction and deployment of quality control procedures (Huws, 2014). Such dynamics have been recognised in the translation industry too, where tendencies towards this so-called Digital Taylorism include the standardisation of jobs to define quality and performance indicators, and the use of technology not only as functional to translation jobs, but also crucial to control the means of production and apply varying levels of monitoring (Moorkens, 2020). The technology that currently enables similar practices of standardisation and control of production and quality in AVT is the cloud platform. This paper attempts to analyse features and practices of professional subtitling in an environment such as this: a phenomenon referred to as platform or cloud subtitling. The point of view adopted in this article is inspired by Actor-Network Theory (Latour, 1987; Law, 1992) as a terminological lens to look at the different actors - human and technological - that populate this landscape, their relationships, and what these entail. In particular, this article analyses subtitling practices on cloud platforms, as described in the course of a qualitative interview study with a group of professional subtitlers. Section 2 provides an introduction to cloud platforms and cloud subtitling, and section 3 then moves on to the study design and methodology. Two particular aspects will be taken in consideration, namely, job assignment (section 3.1) and quality assessment (section 3.2), which will lead to considerations concerning the cloud platforms' communication patterns (section 4). This article contends that paid subtitling practices on cloud platforms are a direct representation of Digital Taylorism, and that the interactions currently available on platforms can generate unsustainable work systems in that they affect the subtitlers' position negatively, primarily as far as communication and trust-building are concerned.

\section{Cloud platforms and production networks}

In general, platforms are "digital infrastructures that enable two or more groups to interact" (Srnicek, 2017: 43). They are digital workstations, commonly found on cloud servers, in which tasks occur and can be recorded - the tasks being in this case audio- 
visual translation processes. Platforms also act as mediators amongst the different types of users (ibid.); in sum, platforms provide the hardware and software environment where a high number of actors, mostly freelancers, can access and process audio-visual content from all around the globe.

The origins of cloud subtitling can be traced back to online communities of volunteer translators who found in the cloud an ideal solution to share materials and ideas amongst large groups and streamline complex translation processes such as subtitling workflows (García, 2015). Around 2008, however, companies started exploiting these online phenomena and the possibilities of the crowd, giving rise to a new type of translation marketplace which was no longer focused on the translators and their needs, but the clients', combining the convenience of a virtual workspace with technological innovations and the management of "the broadest possible pool of paid translators" (ibid.: 24). It might be important to specify that in this case, the term "client" refers to the content producers and/or distributors, and therefore the ones who originate the request for the translation and localisation of their audio-visual content. In the case of the contemporary translation and AVT industry, cloud platforms constitute a common working model for many freelance translators (Díaz Cintas and Massidda 2019; Pielmeier and O'Mara 2020; Bywood 2020; Bolaños-García-Escribano and Díaz Cintas 2020). The focus on client is visible in that most of the current cloud platforms are advertised as safe for the clients' content, as they offer hi-tech data encryption for the safe storage of copyrighted materials, and sometimes a dedicated area that allows clients to monitor the status of projects. At the same time, the focus on translators seems to be lower and at risk, according to translators' fears of depersonalisation and loss of professional agency as will be argued in section 5 (Pielmeier and O'Mara, 2020; Moorkens, 2020).

The principles behind crowd-based work - namely the potential use of large amounts of translators and their application within the virtual environment offered by cloud platforms - have contributed to the business model that emerged from the participants' responses. The dynamics that will be described here occur within what is referred to as a platform model, as opposed to more traditional practices defined as a pipeline model. In the pipeline model, "an LSP receives an order from a client and commissions it to a freelance translator [engaging in] step-by-step arrangement for creating value, with the translator at one end and the client at the other" (Sakamoto, 2018: 87). Conversely, the platform model sees LSPs reinforcing their centrality by adopting a virtual working environment as the only intermediary between clients, internal teams and large pools of outsourced translators (Srnicek, 2017). Consistent with the tendencies of Digital Taylorism mentioned above in section 1, all LSPs working on the cloud have common traits, such as the obligatory and exclusive use of the LSP's cloud technology. In fact, when accepting an assignment for a platform based LSP, that assignment must be carried out exclusively on the platform, and under no circumstances are the translators allowed to use other technical tools to perform tasks for that assignment. Such requirements are primarily linked to the copyright-protected nature of the material and the necessity for LSPs to maintain content safety, but they are also driven by the need for technical consistency in terms of file formats to comply with client specifications. Other features of the platform model include a lack of face-to-face communication and interpersonal relationship 
between human actors, the standardisation of practices and rates, the distribution of smaller tasks across a larger number of actors, and the tendency to centralise and automate both project and quality management (Risku, et al., 2013; Moorkens, et al., 2016; Sakamoto, et al., 2017; García, 2017; Srnicek, 2017; Sakamoto, 2018; Nunes Vieira and Alonso, 2019).

As cloud platforms become more and more present in the commercial provision of subtitles, the interaction with the literature above revealed their inextricable link with economic business models and the production networks that can arise within these. In my opinion, exploring current production networks and the key role of technology required the consideration of social and organisational factors through a qualitative lens. The nature and implications of translation production networks have been widely explored in the last decades in Translation and AVT Studies through a qualitative and socially oriented methodology. In 2007, Abdallah and Koskinen investigated a pipeline business model based on outsourcing and subcontracting, which saw the translation company (LSP) as intermediary (Abdallah and Koskinen, 2007). Their contribution, obtained with an ethnographic method and through interviews with professional translators, defined production networks as a series of 'hubs' connected to one another (clients and LSPs) and to which 'nodes' (translators, linguists, etc.) are attached and dependent. In this setting, they specify that "the end client might be several links away from the actual translator, with no contact or interaction between them" (2007: 677). Abdallah and Koskinen's considerations maintain that the main vulnerability of production networks is the inability to generate a sufficient level of trust, which is crucial for the most exposed and peripheral links - those with the freelancers. Indeed, the authors draw a picture that is very close to the cloud environment in which the interviewed freelancers currently operate. Another crucial study in this area is that of Abdallah (2011), who contributed greatly to socially oriented and qualitative studies in AVT literature with an agency, and Actor-Network-based exploration of the working conditions and relations of a group of subtitlers in Finland. She describes outsourcing and subcontracting practices, pointing to asymmetric relations within the production network, a situation in which information and quality principles were not equally shared - or aligned - across the different actors which populated the working environment. This angle, informed by economic and organisational aspects, acquired a particular relevance in the study presented in this article, as there is a close correspondence to the subtitlers' position within a production network in which communication is hindered and does not flow freely amongst the actors (Abdallah, 2010; Drugan, 2013).

The link between the current platform business model and its implications for communicating information and building trust, will prove to be particularly relevant in the analysis of the findings presented in section 4. The data gathered points to communication and information patterns which, as will be analysed and argued in the following sections, can place translators in a peripheral position, with negative effects on their professional status, as acknowledged by many in translation literature (especially Dam and Zethsen, 2008; Dam and Zethsen, 2016; Katan. 2009, 2011; Kushner, 2013). 


\section{Study outline}

The data presented here reflects the experiences of 6 professional subtitlers, collected in semi-structured interviews carried out as part of my $\mathrm{PhD}$ thesis, a wider qualitative exploration on quality and technology in current subtitling production. In order to obtain a more comprehensive picture of the subtitling production network I needed knowledge from those at the heart of AVT production, that is, the freelance subtitlers, translators and proof-readers. I chose a qualitative methodology with face-to-face interviews so as to directly access their voice, which is too often neglected, and gather in-depth insights about how individuals relate to their subtitling work and technology. The interpersonal dimension allowed me to ask questions about how they work and negotiate their position in their production networks, their perceptions of the quality of their work and working conditions, and the quality of interaction with the workflow and the related technology.

The interviews were semi-structured and the choice of questions revolved around five main themes which had emerged from previous investigations, focusing on the quality of subtitling processes. These were: 1) workflow and communication structure; 2) performance of technology actors, and quality of interaction; 3) time to complete a task; 4) quality of working material; and 5) quality of working conditions and presence of stress factors. The questions for the freelance subtitlers were modelled upon these five categories, adding questions that related to the participants' profile, with a focus on working experience, education and training. The interviews, carried out between 2019 and 2020, consisted of a predefined list of questions, and on average lasted 75 minutes each. Four interviews were possible face to face and took place in public spaces, while two interviews had to be conducted online due to the restrictions imposed by the Covid19 pandemic.

The choice of respondents followed the principle of convenience, where professional subtitlers who were known to me or my network were selected on the basis of their familiarity with freelance subtitling work, and a minimum of 2 years' experience (which was considered sufficient to gather perceptions and data about cloud subtitling specifically, as the younger subtitlers were already very familiar with this working modality). Albeit small, the sample is diverse in terms of age, gender, level of experience and education, therefore the data discussed here attempts to represent views from the average professional subtitler.

\begin{tabular}{|c|c|c|c|c|c|c|}
\hline Pseudonym & Mimi & Carl & Alma & Edie & Zachary & Katia \\
\hline Age range & $25-30$ & $25-30$ & $25-30$ & $35-40$ & $35-40$ & $55-60$ \\
\hline Years of experience & 2 & 3 & 3 & 8 & 12 & $30+$ \\
\hline N. of platforms & 1 & 2 & 2 & 1 & 2 & 1 \\
\hline
\end{tabular}

Table 1. Overview of respondents

Each of them worked for different clients and at the time of interview was working within (or had experienced) either one or two cloud platforms, for a total of five different 
platforms, and so the data presented here looks at the average features of globalised cloud subtitling environments. Three of them, namely the most experienced subtitlers, had previously experienced in-house subtitling models, then were outsourced and hired as freelancers in pipeline business models, and now were working predominantly on platform models. All testimonies highlight that cloud platforms are the most common work environment for them and point to some critical factors of the platform model. The following sections will deal with two specific aspects of cloud subtitling: the automation of job assignments and the management of quality. These two topics were chosen on the basis that they are both steps that require the application of experience-based knowledge and qualitative judgement from the part of the LSP and project managers, and are both being increasingly automated and standardised under the platform model. Automation and standardisation choices appear to be crucial to managing large volumes of content, as opposed to an ad-hoc management, however they also have serious repercussions for the quality of the subtitlers' working conditions, as will be seen below.

\subsection{Study results: Job assignment and communication}

The first feature of cloud subtitling described and analysed here relates to the assignment of subtitling jobs. In fact, the interviews revealed increasing automation in the assignment of jobs, confirming the tendencies towards automation of project management and lack of interpersonal communication that had been already observed in studies into the translation industry (Risku, at al. 2013) and the relationships between translators and project managers (Rodríguez-Castro, 2013; Sakamoto and Födisch, 2017). As reported by the interviewees, subtitlers log into the platform, where they can see a list of available jobs filtered according to the language combination and matched via algorithms to those who fit the project requirements and availability. Subtitlers read the information given for each project, choose one to work on and assign it to themselves.

The most experienced subtitlers were generally satisfied with this system because their client base allowed them to choose the most profitable jobs on the platforms and intersperse them with other projects coming from other direct clients or agencies. In contrast, subtitlers with less experience, or who nevertheless relied on platforms for all or most of their subtitling workload, were more critical towards automated assignment. Edie specified that, while she found it quick and user-friendly, it only worked for her because subtitling was her second occupation - otherwise, making a full-time living through one platform only would be very hard, in her opinion. In fact, projects are assigned on a "first come, first served basis", implying that full-time freelance subtitlers need to check their platforms' dashboards and emails constantly, and might have little time to select projects for which they have received little information. Two other platform users experienced drawbacks with this system, because once a project is accepted, the deadline countdown starts automatically. While the same can be said for non-automated forms of assignments, it is common for project managers (PMs) and translators to discuss a project before the actual start date, which gives freelancers the possibility of moving deadlines and planning their workload over a longer time basis, something which proves hard to do with automated assignments. This is what Carl experienced: 
"Picking up work becomes a challenge, as most clients are American and post the jobs at US time. I check my dashboard at $11.30 \mathrm{pm}$ and grab some work to do the day after: if I wait for the morning, I get the scraps. But once I accept assignments, the deadline countdown starts, and I have less hours to complete it because it's night-time for me."

Most projects are automatically filtered by language before appearing on the subtitlers' dashboards according to their availability. The filtering criteria that facilitate the automation of job assignments are usually inserted by client and/or project managers when loading and indexing the working materials onto the platform. Although the principles of assignment (language, estimated level of quality, availability) might follow the same principles as they do in a more traditional translation agency, personalised contact with PMs is no longer deemed necessary; this is seen as negative by half of respondents, who wished they had more visibility in the whole process and more of a relationship with their PM. As mentioned earlier in the methodology section, the most experienced half of the sample had previously worked in-house (for 2, 5 and 12 years) and spontaneously reported about their experience of job assignments and how they related to the communication patterns in the office. These interviewees suggested that they used to have much more visibility in working practices (and their criteria) when they worked in-house, and assigning jobs was seen as a collaborative task: individual availabilities and specialisations were considered ad-hoc in the workplace and briefly discussed amongst the team before assigning. Nevertheless, in-house positions no longer constitute the norm amongst the freelancers interviewed. At the time of the interviews, the most experienced respondents had left (or were made to leave) their in-house positions several years before, while the younger and less experienced had always worked exclusively with pipeline and/or platform models.

In terms of communication, some degree of visibility and interpersonal interaction is found in pipeline relationships, where freelancers communicate on a regular basis with project managers who notify them of upcoming or urgent projects, potential extensions or other conditions that inform the subtitlers' decision to accept or reject projects (Sakamoto, 2018). Indeed, the PM's skilful mediation between clients' needs and translators' competences and experience has been considered crucial in the success of a translation project. Furthermore, being able to exchange information on projects, availabilities and respective needs between translators and project managers contributes greatly to long-term and trustful working relationships (Abdallah and Koskinen, 2007; Olohan and Davitti, 2017), which in turn facilitate the negotiation of rates and deadlines, according to all subtitlers interviewed.

In this regard, it appears that automated job assignment lowers or removes the possibility for freelance subtitlers to negotiate their rates and deadlines for each assignment, as content is very varied and might call for different degrees of effort depending on the genre, or how many subtitles it contains. While it is true that in pipeline relationships the translators' standard rate is taken as the basis for all jobs, that does not exclude the possibility of negotiating terms and rates ad-hoc, especially if the work has a short deadline or it is very technical. This is what happens to two thirds of the respondents when they do work for other clients via a pipeline model: when asked about rates and deadlines, the main issue that emerged from the subtitlers' responses 
is the actual possibility of communication leading to negotiation. With the automated assignment system, negotiation is restricted: subtitlers can enquire about negotiating pay or deadlines to (often unknown) PMs by submitting a ticket on the cloud platform, but it might take some time for the PM to respond, during which the job is likely to have been taken by someone else. In addition, five out of six respondents stated that the little communication they had about rates was on a "take it or leave it" basis, which has led them to not feeling comfortable about discussing the issue again; similar findings were reported by Kuo (2015). It is also worth mentioning that platform freelancers often do not have direct email addresses for their PM (according to half the respondents) and very importantly, they have little information about the project and no access to a sample of the file in order to make an informed decision. Half of the respondents experienced frustration and difficulties when accepting projects through an automatic assignment system, because they could not know in advance the number of subtitles to be translated in a given file, nor find out whether the terminology was highly technical or not. They felt deprived of key information which would have allowed them to make a well-informed decision about whether the project was suitable for them, information that ultimately determines the level of quality that can be delivered within the deadline (Abdallah, 2011). The restricted communication patterns leading to the shortage of information constituted overall a source of stress for two thirds of the respondents, as information needed to be complemented with platform communication which took away precious time from their deadline and was often not as effective as a personalised or direct relationship the PM, although remote (let alone as the face-to-face communication that some had experienced in the old days of in-housework). In addition, they all commented thatconsidering the time spent explaining issues via the platform, and waiting for a response, their standard, non-negotiable rates were too low.

On the basis of this, I argue that automating the assignment of jobs considerably reduces communication and negotiation opportunities for subtitlers, as they are required to interact with an inanimate system where the human input from the LSP is hidden behind a platform. This contributes to a situation in which information is not sufficiently communicated, leading to information asymmetry (Akerlof, 1970) which can ultimately result in issues of building trust in working relationships (Abdallah and Koskinen, 2007), as will be explored in section 4.

\subsection{Study results: Quality management}

As stated earlier, the other feature of cloud subtitling described and analysed here is the management of subtitling quality. The centralisation of project and quality management found in the platform business model goes hand-in-hand with the fragmentation of jobs into smaller tasks, which are then assigned to a large number of actors. Consistent with Taylorist principles, such fragmentation implies breaking down jobs into smaller units in order to manage them more flexibly, apply performance indicators in each unit and model quality control measures on those indicators so as to maintain and improve productivity - and ideally quality (Huws 2014). In the professional subtitling context under study, this fragmentation is found in the template-based workflow. The template file was already in use long before platforms as a standardisation measure 
aimed at reducing post-production work (and therefore time) by providing an English subtitling file with a predefined timecode, which may or may not be modified by the subtitler (Artegiani and Kapsaskis, 2014; Nikolić, 2015, Oziemblewska and Szarkowska, 2020). In cloud subtitling workflows, all template files are subject to one or more rounds of quality control (QC) before being translated; then, the translations undergo proofreading, revision and ideally at least one QC stage. The more fragmented the workflow, the more complex it becomes to manage quality, as more actors are responsible for each file in each step of the process, as well as the quality that has to be delivered at each step.

Each time that controllers and proof-readers review the files, they apply error codes whenever they encounter issues by selecting the error category they deem appropriate (usually from a dropdown list). They might add a short comment to explain their choice, before submitting the file on the platform, where the translator will be notified to accept or reject corrections. Respondents stated that in cloud subtitling, when proof-readers and QCers assign error points to a translation, this automatically generates not only an error report attached to that file, but also to the translator's profile. Half of the subtitlers commented that such reports provide little qualitative feedback: they receive a spreadsheet with the number of errors by category, sometimes accompanied by telegraphic comments. These statistics create data that rank the performance of the freelancers, and the error rate of single files as well as whole projects. If their error count increases, the LSP would contact subtitlers and offer extra training according to the error category they hit the most. They also reported that the communication of errors was the sole reliable form of communication (and the only type of feedback) that they received when working for some platform LSPs, especially larger ones.

Carl and Edie were worried about how their ratings were used in the LSP and their concerns were not fully addressed by their PMs. Edie's project manager told her "not to worry", nevertheless she felt that she needed more information in order to trust her PM (with whom she rarely had email exchanges), as she believed that her position at the LSP was determined by those numbers. Edie also recalled one time when she experienced high error counts on her files and asked her project manager to put her in contact with the QCer, something that was not allowed by company policy. Nevertheless, she repeatedly raised this issue with her PM, as those error counts were affecting her performance rating, and she feared that they could affect her position at the agency. After several requests, the PM put Edie and the QCer in contact:

"We were soon able to resolve a misunderstanding around a lexical choice, and the project went smoothly from that point onwards; I learnt enormously from collaborating closely with the QCer, and the quality of files in that project improved so much because of that communication."

However, this was an isolated occasion and she was not able to achieve the same degree of collaboration again. Both Edie and Carl reported that the rating system was a source of psychological stress for them because every time a proof-reader or QCer reviewed a subtitler's file, they could potentially impair the subtitler's performance and position at the LSP. What was especially frustrating for the respondents was not being able to discuss issues with others working on the project as a means for finding solutions. 
It seemed that the limited communication amongst freelancers working on the same project files and the overall restricted transparency attached to this practice, further added to this stress. Although they understood that, albeit desirable, a more personalised, constructive and detailed feedback for every project would be unfeasible in those working conditions, they both nevertheless added that this feedback system did not help them as it was not specific enough, it could not be discussed with the proof-reader or controller and, in their opinion, it was not managed with enough clarity from the project managers' side. Indeed, as already noted by Risku et al (2013), in their comparative study on translation processes in the so-called 'digital network economy', production networks have increasingly become virtual working environments. Noticing that companies turned to digital platforms to streamline collaboration and communication with clients and providers, the authors highlight how this phenomenon has limited the range of personal approaches to translation work (ibid.) - a consideration which becomes fundamental in light of the data presented here. Furthermore, the majority of the subtitlers interviewed expressed a perceived tendency of LSPs to blame the translator for any loss of quality (consistent with reports by Sakamoto and Födisch, 2017) with an attitude that seemingly created resentment amongst the various outsourced freelancers.

According to the respondents, these feelings were exacerbated not only because they could not contact the other translators to discuss the nature of certain translation problems, or the reasons behind any given negative feedback, but also because it was difficult to discuss those issues with their PM and receive personalised or reassuring answers. The fact that communication and interaction between translators and proofreaders working on the same project (and often the same files) is not facilitated or is even prohibited can also have negative repercussions on the final quality of files, as more back-and-forth communication through PMs is needed, which means more time (and thus more hurried translations), to compensate for the lack of direct communication. Edie, Carl and Katia reported feelings of isolation while working on platforms, and frustration associated with not being able to communicate issues and solutions freely with colleagues before a file was delivered, and for which translators were rated and ranked.

\section{Implications of cloud subtitling communication patterns}

What emerges is that the flow of interpersonal communication seems to be heavily filtered and often impaired in cloud subtitling, as PMs managers and translators become estranged or invisible to one another, and unlikely to be able to forge any degree of familiarisation between them. The data collected aligns with the view that automated workflows are a characteristic of complex production networks within what Abdallah and Koskinen (2007) and Srnicek (2017) define as businesses that rely heavily on outsourcing, and therefore on actors who are geographically dispersed. The authors maintain that in these types of business models, the company structure and the virtual dimension of translation do not support horizontal links between the outsourced actors that are individually linked to the LSP. This is because too much information sharing between the peripheral actors might affect the centralisation of the LSP (Abdallah and Koskinen, 
2007). It follows that the automation of key tasks such as job assignment, and the fact that project managers are considerably less visible and available, further prevents the symmetrical distribution of information. Not having direct communication options - and therefore shared access to information - is detrimental to the relationship of freelancers with their PM and LSP (Olohan and Davitti, 2017) and building a trustful collaboration between them, as "trust entails that each of the actors' perspectives and interests are addressed, that knowledge is shared, and that information is clear, accountable and legitimate" (Abdallah and Koskinen, 2007: 678).

In sum, the communication between freelancers and the LSP's project managers is mostly restricted to the feedback attached to ranking and rating, and freelancers are generally not allowed to communicate freely through the platform. Furthermore, they are given little information on the projects prior to assignment, there is no sample to view, and usually no one readily available to answer their questions before a job is accepted. This situation can be explained in economic theory as an "asymmetry in available information" (Akerlof, 1970: 489), a phenomenon in which actors withhold information from others, which complicates business transactions in the sense that it requires the less informed actors to base their decisions on estimates. Asymmetric communication patterns are described by Chan (2005), Abdallah (2010) and Dunne (2012) as conditions that can generate a loss in quality in translation environments, because if different, uncommunicating actors are located in different premises and in different countries (or continents) and cannot freely access joint information, they would have limited tools to assess the project beforehand, discuss quality expectations, and choose the right resources.

In environments where information is distributed asymmetrically, translation buyers in this case the LSPs - do not know their translators personally nor are they always skilled in translation assessment, and therefore need to find solutions to distinguish good translations from bad (Dunne, 2012). The rating and ranking system described above for quality assessment seems the only solution that the industry found to evaluate the work quality of thousands of outsourced actors. In addition, the fact that, in principle, PMs would not speak most target languages within a project severely limits their ability to keep an eye on the quality of the translations, or easily understand possible issues raised by subtitlers. Actually, apart from continued collaboration, the signals of subtitlers' trustworthiness (certifications, professional or academic accreditations, degrees, portfolio, and entrance test) do not guarantee that they will continue to deliver quality consistently (Chan, 2005; Olohan and Davitti, 2017). The subjective evaluation that project managers carry out in pipeline models is therefore eliminated from the cloud subtitling model, possibly out of unsustainability due to the large numbers of projects and freelancers. Not being able to personally know the freelancers' skills and working habits reveals once again that platform subtitling is an environment where information asymmetry is deeply rooted, and therefore the rating and ranking system can substitute the experience-based knowledge of project managers with figures (that are picked up by the automated job assignment algorithm), aimed at representing the freelancers' performance and ability to deliver quality. 
At the same time, such ratings and rankings also provide evidence on how well the LSP is performing in terms of quality of outputs, which can be used by companies to defend their position in the market: since content producers have no solid way of assessing the vendors' quality output and trustworthiness except through experience (Akerlof, 1970), LSPs need a way to signal their status and prove they can maintain their reputation with the client. In sum, the rating and ranking system is being deployed by some LSPs to maintain and control quality levels across outsourced actors, and then use those results - combined with client feedback - to certify and signal their own trustworthiness in the market. This is only possible through an infrastructure that allows its owner to record activities which automatically generate performance and productionrelated data (Srnicek, 2017). It follows that working on a cloud platform means that huge quantities of performance data, including all data about errors, client's rejections and feedback, are available for processing by the platform owner. This is an issue that might raise questions around data collection, management and safety that could be addressed in future research. The collected ratings should enable content producers to make informed decisions when choosing LSPs, and LSPs to make informed decisions when it comes to translators. It appears, however, that translators - who are effectively at the core of this service - are those who can make the least informed decisions about their work, as they are required to operate with little information before projects are assigned, and are subject to restrictive communication and negotiation patterns, and little transparency concerning the ranking and rating system.

The interviewed subtitlers confirm that the automation of workflows and quality assessment is experienced by all of them, and so this phenomenon seems increasingly common in cloud subtitling. While this study contributes to shedding light on the underresearched phenomena of cloud subtitling, it should also be noted that these systems, while widespread in this sector, do not reflect the specificities of subtitling translation and could also be found in platforms that mediate other translation modalities. Rather, practices of standardisation and automation and their impact on patterns of communication and the flow of information relate closely to work management in the platform business model. This raises questions about the suitability and sustainability of such models in AVT production networks regarding the extent to which audio-visual translation specificities are factored into the technology design, and in the organisation and management of work. At the same time, this also implies that some of the findings and principles of analysis expressed here can be applied and therefore contribute to social and organisation-oriented research outside audio-visual translation, and within the wider discipline of Translation Studies.

\section{Conclusion}

I argue that the design of professional AVT cloud platforms actively discourages communication, negotiation and interaction, thus impeding real collaboration and trustbuilding amongst the different parties involved. In light of this, I contend that the management of mainstream and global subtitling projects under a platform business model is not sustainable as it does not support the needs of all the actors involved - 
and for this reason it requires a heightened focus on organisational as well as social and communicational aspects. Research in the area could open up to economic, organisational, and social perspectives to find alternative business and production models, and propose effective communication and collaboration, as these are widely considered key elements for successful projects (Gummerus and Paro, 2001; Abdallah and Koskinen, 2007; Kuznik and Verd, 2010; Di Giovanni, 2016). Importantly, it is crucial for organisations to address the issues of information asymmetry, thus recognising the relevance of communication and collaboration to improve quality in processes and products - as these can be attained only when actors have access to joint information (Chan, 2005; Abdallah, 2010; Dunne, 2012).

The analysis of information and communication patterns points to a system of unsustainability, understood as the inability to equally meet the professional and communicational requirements of the various actors in the network. This is visible in numerous interrelated aspects: this study confirms that information asymmetry can produce stress, affect the subtitlers' job satisfaction, and prevents the establishment of a trusted collaboration between actors (Abdallah and Koskinen, 2007; Olohan and Davitti, 2017), which is directly related to the subtitlers' position in the production network, their motivation and the quality they produce. On a practical level, the lack of communication and actual collaboration undermines the quality of apparently "collaborative" projects, to which dozens of actors are asked to contribute. On a deeper level, it connects with the crucial role of trust, inextricably linked to communication patterns (such as the inability to freely communicate with PMs and colleagues) and essential for translators to exercise their agency (i.e., when negotiating their working conditions, which are arguably as good as their negotiability). Ultimately, a lack of trusted collaboration can result in subtitlers feeling marginalised and isolated within the production network, as found in the study as well as in literature (Abdallah and Koskinen, 2007; Abdallah, 2010; Moorkens, 2017; Sakamoto and Födisch, 2017). Feelings of isolation from PMs and fellow translators / proof-readers working on the same project can lead to the disempowerment of freelancers. Linked to the low possibilities of association and collective bargaining (Moorkens, 2017), this scenario is worsened by the ranking system which could pitch freelancers one against the other. The increased marginalisation of the translators' professional figures has been consolidated by the platform business model, and I argue that automation plays a crucial role in centralising the LSP while at the same time isolating freelancers and even those working on the same project. This leads to each actor working within their "pocket of knowledge", as one responder aptly expressed, without the training and learning possibilities that result from human collaboration, as this article has shown. This is an aspect that has been identified as carrying serious risks of deskilling, but also points to the potential replaceability of outsourced actors by other actors with the same, limited "pocket" of knowledge (Dunne, 2012; Jiménez-Crespo, 2018; Moorkens, 2021).

I maintain that it is crucial to research and improve the social and organisational aspects of communication in translation networks, as well as working on the role of technology - instrumental in coordinating translation labour globally - in a way that analyses the subtitlers' needs, and also caters for clients' requests. Processing large 
volumes of work with a wide range of different actors who are barely visible and accessible to one another, is indeed a considerable challenge for current production networks. However, it has to be recognised that automating the assignment of jobs and quality management (two key practices which require the application of experience-based knowledge, soft skills and qualitative judgements) can lead to quantitatively positive outcomes. Nevertheless, it needs to be equally acknowledged that this way of employing automation does have adverse effects on the sustainability of this model in that it impairs the subtitlers' visibility and prominence in the system, and ultimately could affect the quality of products and processes. Understanding these effects is the first step towards a renewed approach to professional subtitling that encompasses communication and collaboration in the interests of fairer working conditions as well as translation quality, without necessarily denying the benefits of automation technology.

\section{Bibliography}

Abdallah, K.; Koskinen, K. (2007). Managing Trust: Translating and the Network Economy. Meta: Translators' Journal, v. 52, n. 4, pp. 683-687. 〈doi:10.7202/017692ar〉. [Accessed: 20211113].

Abdallah, K. (2010). Translator's agency in production networks. In: Kinnunen T.; Koskinen, K. (eds.). Translators' Agency. Tampere: Tampere University, pp. 11-46. 〈https://trepo.tuni.fi/bitstream/handle/10024/65639/978-951-44-80829.pdf?sequence=1\&isAllowed=y $>$. [Accessed: 20211113].

Abdallah, K. (2011). Quality problems in AVT production networks. In: Serban, A.; Matamala, A.; Lavaur, J. M.; (eds.). Audiovisual Translation in Close-Up: Practical and Theoretical Approaches. 2nd edition. Bern: Peter Lang.

Akerlof, G. A. (1970). The Market for "Lemons": Quality Uncertainty and the Market Mechanism. The Quarterly Journal of Economics, v. 84, n. 3, pp. 448-500. <doi: 10.2307/1879431>. [Accessed: 20211115].

Artegiani, I.; Kapsaskis, D. (2014). Template files: asset or anathema? A qualitative analysis of the subtitles of The Sopranos. Perspectives, v. 22, n. 3, pp. 419-436. 〈doi: 10.1080/0907676X.2013.833642〉. [Accessed: 20211115].

Bolaños-García-Escribano, A.; Díaz Cintas, J. (2020). The Cloud Turn in Audiovisual Translation. In: Bogucki Ł.; Deckert, M. (eds.). The Palgrave Handbook of Audiovisual Translation and Media Accessibility. Cham: Springer International Publishing, pp. 519544.

Bywood, L. (2020). Technology in Audiovisual Translation. In: Bogucki, Ł.; Deckert, M. (eds.). The Palgrave Handbook of Audiovisual Translation and Media Accessibility. Cham: Springer International Publishing, pp. 513-517.

Chan, A. (2005). Why Are Most Translators Underpaid? A descriptive explanation using asymmetric information and suggested solution from a suggested solution from 
signalling theory. Translation journal, v. 9, n. 2.

〈http://www.bokorlang.com/journal/32asymmetric.htm〉. [Accessed: 20211115].

Dam, H; Zethsen, K. (2008). Translator Status. The Translator, v. 14, n. 1, pp. 71-96. 〈https://www.tandfonline.com/doi/abs/10.1080/13556509.2008.10799250〉. [Accessed: 20211108].

Dam, Helle; Zethsen, K. (2016). «I think it is a wonderful job»: On the solidity of the translation profession. JoSTrans, The Journal of Specialised Translation, n. 25, pp. 174-187. 〈https://www.jostrans.org/issue25/art_dam.pdf〉. [Accessed: 20211115].

Di Giovanni, E. (2016). The layers of subtitling. Cogent Arts \& Humanities, v. 3, n. 1. 〈doi: 10.1080/23311983.2016.1151193〉. [Accessed: 20211113].

Díaz-Cintas, J.; Massidda, S. (2019). Technological advances in audio-visual translation. In: O'Hagan, M. (ed.). The Routledge Handbook of Translation and Technology. London: Routledge, pp. 255-270.

Drugan, J. (2013). Quality in professional translation: Assessment and improvement. London [etc.]: Bloomsbury.

Dunne, K. J. (2012). The industrialization of translation: Causes, consequences and challenges. Translation Spaces, v. 1, n. 1, pp. 143-168. 〈doi: 10.1075/ts.1.07dun〉. [Accessed: 20211113].

García, I. (2015). Cloud marketplaces: Procurement of translators in the age of social media. JoSTrans, The Journal of Specialised Translation, n. 23, pp. 18-38. 〈https://www.jostrans.org/issue23/art_garcia.pdf〉. [Accessed: 20211115].

García, I. (2017). Translating in the Cloud Age: Online Marketplaces. Hermes, Journal of Language and Communication in Business, n. 56, pp. 59-70. <https://doi.org/ 10.7146/hjlcb.v0i56.97202>. [Accessed: 20211115].

Gummerus, E.; Paro, C. (2001). Translation Quality: An Organizational Viewpoint. In: Gambier Y.; Gottlieb H. (eds.). (Multi)Media Translation. Amsterdam: John Benjamins. (Benjamins Translation Library; 34), pp. 133-142. 〈https://doi.org/10.1075/btl.34.16gum〉. [Accessed: 20211115].

Huws, U. (2014). Labor in the global digital economy: The cybertariat comes of age. New York: Monthly Review Press.

Jiménez Crespo, M. (2018). Crowdsourcing and translation quality: Novel approaches in the language industry and translation studies. In: Moorkens, J.; Castilho, S.; Gaspari, F.; Doherty, S. (eds.). Translation Quality Assessment: From Principles to Practice. Cham: Springer, pp. 69-93.

Katan, D. (2009). Translation theory and professional practice: A global survey of the great divide. Hermes, Journal of Language and Communication Studies, v. 22, n. 42, pp. 111-153. 〈doi: https://doi.org/10.7146/hjlcb.v22i42.96849〉. [Accesses: 20211115]. 
Koskinen, K.; Ruokonen, M. (2017). Love letters or hate mail? Translators' affective responses to technology. In: Kenny, D. (ed.). Human Issues in Translation Technology. Milton Park [etc.]: Routledge. 〈doi: 10.4324/9781315648934〉 [Accessed: 20211007].

Kuo, A. S. (2015). Professional Realities of the Subtitling Industry: The Subtitlers' Perspective. In: Baños Piñero, R.; Díaz Cintas, Jorge. (eds.). Audiovisual translation in a global context: Mapping an ever-changing landscape. Basingstoke: Palgrave Macmillan, pp. 163-191. 〈doi: 10.1057/9781137552891_10〉. [Accessed: 20211020].

Kushner, S. (2013). The freelance translation machine: Algorithmic culture and the invisible industry. New Media \& Society, v. 15, n. 8, pp. 1241-1258. $\langle$ https://doi.org/10.1177/1461444812469597〉. [Accessed: 20211007].

Kuznik, A.; Verd, J. M. (2010). Investigating real work situations in translation agencies: Work content and its components. Hermes, Journal of Language and Communication in Business, n. 44, pp. 25-43. 〈https://doi.org/10.7146/hjlcb.v23i44.97263〉. [Accessed: 20211020].

Latour, Bruno (1987). Science in action: how to follow scientists and engineers through society. Cambridge, MA: Harvard University.

Law, John (1992). Notes on the Theory of the Actor-Network: Ordering, Strategy and Heterogeneity. Systems Practice, n. 5, p. 379-393.

Moorkens, J.; Lewis, D.; Reijers, W.; Vanmassenhove, E.; Way, A. (2016). Translation resources and translator disempowerment. In: Tenth International Conference on Language Resources and Evaluation (LREC 2016), 24-28 May, Portorož, Slovenia.

Moorkens, J. (2017). Under pressure: translation in times of austerity. Perspectives, v. 25, n. 3, pp. 464-477. 〈https://doi.org/10.1080/0907676X.2017.1285331〉. [Accessed: 20211020].

Moorkens, J.; O'Brien, S. (2017). Assessing User Interface Needs of Post-Editors of Machine Translation. In: Kenny, D. (ed.). Human Issues in Translation Technology. Milton Park [etc.]: Routledge. 〈https://doi.org/10.4324/9781315648934〉. [Accessed: 20211007].

Moorkens, J. (2020). "A tiny cog in a large machine": Digital Taylorism in the translation industry. Translation Spaces, v. 9, n. 1, pp. 12-34. 〈https://doi.org/10.1075/ts.00019.moo〉. [Accessed: 20211007].

Moorkens, J. (2021). Translation in the Neoliberal Era. In: Bielsa, E.; Kapsaskis, D. (eds.). The Routledge Handbook of Translation and Globalization. London: Routledge. <https://doi.org/10.4324/9781003121848>. [Accessed: 20211007].

Nikolić, K. (2015). The pros and cons of using templates in subtitling. In: Baños Piñero, R.; Díaz Cintas, Jorge. (eds.). Audiovisual translation in a global context: Mapping an ever-changing landscape. Basingstoke: Palgrave Macmillan, pp. 192-202. <doi: 10.1057/9781137552891_11> [Accessed: 20211012]. 
Nunes Vieira, L.; Alonso, E. (2019). Translating perceptions and managing expectations: an analysis of management and production perspectives on Machine Translation. Perspectives, v. 8, n. 1, pp. 163-184. 〈https://doi.org/10.1080/0907676X.2019.1646776〉. [Accessed: 20211007].

Olohan, M.; Davitti, E. (2017). Dynamics of Trusting in Translation Project Management: Leaps of Faith and Balancing Acts. Journal of Contemporary Ethnography, v. 46, n. 4. 〈https://doi.org/10.1177/0891241615603449〉. [Accessed: 20211007].

Oziemblewska, M.; Szarkowska, A. (2020). The quality of templates in subtitling: A survey on current market practices and changing subtitling competence. Perspectives, pp. 1-22. 〈https;//doi.org/10.1080/0907676X.2020.1791919〉. [Accessed: 20211007].

Pielmeier, H.; O'Mara, P. (2020). The State of the Linguist Supply Chain. Boston: Common Sense Advisory.

Risku, H.; Rossmanith, N.; Reichelt, A.; Zenk, L. (2013). Translation in the network economy: A follow-up study. In: Way C.; Vandepitte S.; Meylaerts R.; Bartolomiejczyk, M. (eds.). Tracks and treks in translation studies: Selected papers from the EST Congress, Leuven 2010. Amsterdam: John Benjamins Publishing Company. (Benjamins Translations Library; 108), pp. 29-48. 〈http://doi.org/10.1075/btl.108.02ris〉. [Accessed: 20211007].

Rodríguez-Castro, M. (2013). The project manager and virtual translation teams: Critical factors. Translation Spaces, v. 2, n. 1, pp. 37-62. 〈https://doi.org/10.1075/ts.2.03rod〉. [Accessed: 20211007].

Sakamoto, A.; Födisch, M. (2017). No news is good news? Translation Spaces, v. 6, n. 2, pp. 333-352. 〈https://doi.org/10.1075/ts.6.2.08sak〉. [Accessed: 20211007].

Sakamoto, A.; Rodríguez de Céspedes, B.; Berthaud, S.; Evans, J. (2017). When translation meets technologies: LSP in the digital age: Focus group report. Portsmouth: Institute of Translators and Interpreters. <when-translation-meetstechnologies.pdf hen-translation-meets-technologies.pdf>. [Accessed: 20211007].

Sakamoto, A. (2018). Disruption in Translator-Client matching: Paid crowdsourcing platforms vs Human project managers. Tradumàtica, tecnologies de la traducció, n. 16, pp. 85-94. 〈https://doi.org/10.5565/rev/tradumatica.218〉. [Accessed: 20211007].

Srnicek, N. (2017). Platform capitalism. Cambridge, UK. [etc.]: Polity. 